\title{
A RISK METRIC ASSESSMENT OF SCENARIO-BASED MARKET RISK MEASURES FOR VOLATILITY AND RISK ESTIMATION: EVIDENCE FROM EMERGING MARKETS
}

Innocent Sitima, Clifford K. Hlatywayo *

\section{Abstract}

The study evaluated the sensitivity of the Value- at-Risk (VaR) and Expected Shortfalls (ES) with respect to portfolio allocation in emerging markets with an index portfolio of a developed market. This study utilised different models for VaR and ES techniques using various scenario-based models such as Covariance Methods, Historical Simulation and the GARCH $(1,1)$ for the predictive ability of these models in both relatively stable market conditions and extreme market conditions. The results showed that Expected Shortfall has less risk tolerance than VaR based on the same scenario-based market risk measures.

Keywords: risk metric assessment: market risk measures: risk estimation: risk volatility: emerging market

JEL: $G 11, G 15$

\section{INTRODUCTION}

Globalisation has swayed capital markets and necessitated the need for collaboration of economic trade, which has instigated international markets to be more networked. Global capital markets have frequently affected each other as there is a higher dispersion of international information causing more powerful co-integration in the movement of capital markets in the world, whether developed or otherwise. Extraordinary events in the market often give rise to high losses in the market, and events such as those of October 1987, February 1994 and the more recent subprime mortgage crisis often are the major causes for market distortions in developed markets. The literature (Longin, 2000; Barry \& Rodriguez, 2004; Lee, Shie, \& Chang, 2012), shows that emerging markets suffer many crises stemming from political disturbances or misguided economic policies, among other sources.

Some market crises do not necessarily affect the whole market but rather a small region or a specific country. A regional crisis can be a crash like that of the
Asian tigers in 1999, or an epidemic such as the Asian flu as suggested by Girard et al, (2003). In South Africa these extraordinary situations can be seen in events such as the 2002-2003 rand crisis, erratic labour disturbances and high electricity hikes, which often result in misguided economic policies that tend to affect stock market performance. Some of the factors do not have globally catastrophic effects on markets, although they have regional or even continental effects, considering that South African financial markets are the best performing financial system in Africa. Under such

\section{* Innocent Sitima, PhD candidate}

Department of Agricultural Economics, University of Fort Hare, South Africa, E-mail: innositima@gmail.com

Clifford K. Hlatywayo, PhD candidate Department of Agricultural Economics, University of Fort Hare, South Africa 
a heavy wave of uncertainty on global and domestic frontiers there is a dire need for risk to be mitigated (Premet al., 2010).

Emerging markets, particularly those in Africa, have been neglected by the literature in terms of risk metric assessment. Most emerging markets are basically characterised by heavy tails in their distribution, particularly those of Extreme Value, making emerging markets more volatile and riskier compared to developed markets (Longin, 2000). Gourieroux et al., (2000); Fan et al., (2004); Yamai \& Yoshiba (2005); Cheng et al., (2007), have shown that since the subprime mortgage crisis of 2007-2008, the risk properties of emerging markets have become equally important on global markets. Investors always try to mitigate both capital and credit risk to ensure that portfolios incur a minimum number of losses. Various theories have been put forward to make sure that losses are kept at a reasonable level. In this light numerous theories were brought forward, such as the Value-at-Risk (VaR), Expected Shortfall and Extreme Value (EVs) theories, to mention but a few. Most of these methods seek to measure risk and reduce uncertainty in the market.

On the regulatory side, regulators also have roles in the financial health of the financial system because most regulators are concerned with the condition of the financial system amid extreme events and catastrophic events occurring in the market. Various statutes and pieces of legislation such the Basel I, II and III have been put in place to ensure that banks and financial institutions remain functional and the risk appetites of investment companies is kept at a controlled level (Haas, 2009). Over and above the main problem in risk management has been the issue of risk measurement and how best to quantify the amount of exposure.

This paper seeks to look at the interdependency and concentration of the market risks of financial markets in terms of how the emerging markets relate to some of the best and most advanced markets. To achieve this, the paper will construct a portfolio that comprises investments in emerging market and developed market structures.

\section{THEORETICAL BACKGROUND, CONCEPTS AND LITERATURE}

\section{Value-at-Risk}

Value-at-Risk (VaR) is the statistical analysis of the maximum number of losses that can occur in a given portfolio due to unexpected market movements as a result of an unforeseeable catastrophic event for the market. The main advantages of the $\mathrm{VaR}$ as an estimation technique are its conceptual simplicity, ease of computation and its readiness for applicability (Yamai\&Yoshiba, 2005). The VaR technique allows for both long and/or short-term risk factors and the correlation between the risk factors to be measured during extreme conditions (Longin, 2000). However, most investors and risk managers have been sceptical about the use of $\mathrm{VaR}$ as a risk metric procedure after the 2007-2008 subprime crisis. The $\mathrm{VaR}$ is given as $a$, the confidence interval that a portfolio is not expected to exceed given such an event. Formally, $\mathrm{VaR}$ is given as:

$$
\begin{aligned}
& V_{a}=\inf \{l \in \mathfrak{R}: P(L>l) \leq 1-\alpha\} \\
& =\inf \left\{l \in \mathfrak{R}: F_{L}(l) \geq \alpha\right\}
\end{aligned}
$$

where the given confidence interval is $\alpha \in(0,1)$ and the VaR for the portfolio loss is given by $l$ such that the probability loss of the portfolio $L$ exceeds $l$ and is not bigger than $1-\alpha$ (McNeil et al, 2005), and $F_{L}$ denotes the loss distribution function (Rossignolo, Fethi\&Shaban, 2012). By applying the quartile function the normal VaR function ${ }^{1}$ is given as:

$$
\operatorname{VaR}_{\alpha}=\mu+\sigma \Phi^{-1}(\alpha)
$$

hence $F_{L}\left(\operatorname{VaR}_{\alpha}\right)=\alpha$, giving the linearised loss and risk factor changes. ${ }^{2}$ The main disadvantages of $\mathrm{VaR}$ as a risk metric assessment technique has been that VaR is generally unreliable in assessing a market under stress where the market is generally characterised by a volatile and extreme dependence structure (Yamai\&Yoshiba, 2005). The VaR technique tends to underestimate the risk. Artzner et al., (1997) developed another approach to be used to estimate risk beyond VaR, which is the expected shortfall.

\section{Expected shortfall}

This complementary approach to modelling and measuring loss distribution based on the exposure of a portfolio is now preferred to the VaR technique, as this technique allows risk managers to avoid the problem of non-additives associated with the VaR

\footnotetext{
${ }^{1}$ If the Loss follows a student $\mathrm{t}$ distribution then

$L \sim t\left(v, \mu, \sigma^{2}\right)$ then $\operatorname{VaR}_{\alpha}=\mu+\sigma t_{v}^{-1}(\alpha)$

${ }^{2}$ Assuming the data follows a Gaussian distribution
} 
approach. The Expected Shortfall (ES) is a statistical technique that allows risks to be measured by simply looking at the tail of the distribution of the loss incurred that have exceeded VaR (McNeil et al., 2005). The definition of ES is given as:

$$
E S_{\alpha}=\frac{1}{1-\alpha} \int_{\alpha}^{1} q_{u}\left(F_{L}\right) d u
$$

where $q_{u}\left(F_{L}\right)=F_{L}^{\leftarrow}(u)$ is the quartile function of $F_{L}$ (McNeil et al, 2005), therefore:

$$
\operatorname{VaR}_{\alpha}=\frac{1}{1-\alpha} \int_{\alpha}^{1} \operatorname{VaR}_{\alpha}(L) d u
$$

The main drawback of ES as a risk metric is that it depends on the accuracy of the estimation of the portfolio.

\section{METHODOLOGY}

\section{VaR and ES risk estimation models}

In our analysis, the authors should emphasise that the paper shall use the main (marginal) distributions which are the normal and the student t-distributions for the returns data (see Berger (2013) for discussion). In this analysis the authors assess the risk metric measures using the following models:

\section{Variance-Covariance Model}

This is statistical analysis that allows for the modelling of multivariate normal analysis of both conditional and unconditional methods using risk factor changes:

$$
L_{t+1}^{\Delta}=l_{[t]}^{\Delta}\left(X_{t+1}\right) \sim N\left(-c_{t}-b_{t} \mu, b_{t}^{\prime} \sum b_{t}\right)
$$

where b and c represent random vector constants. ${ }^{3}$

\section{Historical simulation}

The authors apply arguably the simplest form of risk metric by using historical simulation (HS). To stimulate the data using empirical or historical data the HS model allows the multivariate model to be estimated using the loss operators, the assumption being that historical data is actually consistent with

3 See McNeil et al, 2005, chapter 3 the estimator of the current loss operator (McNeil et $a l, 2005)^{4}$ thus, $l_{[t]}(X)$ under $F_{X}$ for larger samples. The more formal definition is given as:

$$
F_{n}(l)=\frac{1}{n} \sum_{s=t-n+1}^{t} I_{\left\{L_{s} \leq l\right\}}=\frac{1}{n} \sum_{s=t-n+1}^{t} I_{\left\{l_{l}\left(X_{s}\right) \leq l\right\}} \rightarrow P\left(l_{[t]}(X) \leq l=F_{L}(l)\right.
$$

\section{GARCH processes}

Financial time series display some stylized facts like the autocorrelation of squared returns and volatility clustering (Rossignoloet al., 2012). It is paramount that the authors use the Generalized Autoregressive Conditional Heteroscedastic (GARCH) process to capture the volatilities of the daily risk-factor return series in the data. The GARCH process has good predictive ability for estimating conditional volatility assuming the processes $\left(X_{t}\right)_{t \in Z}$ is a $\operatorname{GARCH}(p, q)$ process if the model is strictly stationary. The GARCH process is given as:

$$
X_{t}=\alpha_{0}+Z_{t}, \sigma_{t}^{2}=\alpha_{0}+\sum_{i=1}^{p} \alpha_{i} X_{t-1}^{2}+\sum_{j=1}^{p} \beta_{j} \alpha_{t-j}^{2}
$$

where

$\alpha_{0}>0, \alpha_{1} \geq 0, i=1, \ldots \ldots . ., p$, and $\beta_{j} \geq 0, j=1, \ldots \ldots \ldots, q$ . The authors use the low order GARCH $(1,1)$ model, which allows that periods of high volatility tend to be persistent. The authors stimulate realisation of a GARCH $(1,1)$ process with a Gaussian innovation (McNeil et al, 2005). The GARCH $(1,1)$ process is given as:

$$
X_{t}=Z_{t} \sqrt{\alpha_{0}\left(1+\sum_{i=1}^{\infty} \prod_{j=1}^{i}\left(\alpha_{1} Z_{t-j}^{2}+\beta\right)\right)}
$$

The main advantage of the GARCH methodology is that it is very practical in terms of the risk measurement of risk factors. GARCH is relatively simple to use and to apply, and moreover it tends to prove itself very easy to fit.

\section{Back testing and Stressed GARCH}

To assess the validity of the historical simulation model it is imperative that the risk manager should at least conduct a back test to check if the historical simulation procedure is continually implemented over time to compare the performance and the relative performance of the model. At time $t+1$ by

${ }^{4}$ Assuming the stationarity of the risk factor changes 
definition of VaR (assuming a continuous loss distribution) we have $p\left(L_{t+h}>V_{a R_{\alpha}^{t, h}}\right)=1-\alpha$ so that the probability of the default of violations of the $\mathrm{VaR}$ and $\mathrm{ES}$ is given by $1-\alpha$, thus:

$$
\begin{aligned}
& \hat{I}_{t+1}:=I_{\left\{L_{t+1}>\operatorname{Va} \hat{R}_{\alpha}^{t}\right\}}, \\
& \hat{I}_{t+h}^{(h)}:=I_{\left\{L_{t+h}>V a \hat{R}_{\alpha}^{t, h}\right\}}
\end{aligned}
$$

\section{DATA AND EMPIRICAL RESULTS}

\section{Data sources}

Historical daily returns data were calculated using the logarithm difference between daily closing prices from the Data Stream Website for the period from January 2000 to December 2010. To stimulate the level of risk associated with these markets, the paper assumes a hypothetical portfolio invested as follows: the raw data consisted of a portfolio of 10 million USD to invest and borrowed 10 million against the 1-year Treasury Bill interest rate. A third of the portfolio is invested in the South Africa stock index (FTSE JSE). Another third was invested into the Goldman Sachs Commodity Index, while the rest is invested into the Chinese stock market, specifically in the Shanghai Stock Exchange (SSE) Composite Index.

Table 1 shows data analysis of the simulated portfolio. The SSE Composite Index tends to have higher volatility while the FSTE/JSE is less volatile in all data points.

Figure 1 highlights the time series of risk factor changes in the daily log returns on the FTSE/JSE, S\&P 500, and CHSC OMP indices, as well as their currency

Table 1: Descriptive Statistics, 2/1/03-2/1/13

\begin{tabular}{|l|c|c|c|c|c|c|}
\hline & FTSE/JSE & S\&P GSCI & $\begin{array}{c}\text { SHANGHAI SE } \\
\text { COMPOSITE - } \\
\text { PRICE INDEX }\end{array}$ & $\begin{array}{c}\text { US \$ TO SOUTH } \\
\text { AFR. RAND - } \\
\text { EXCHANGE RATE }\end{array}$ & $\begin{array}{c}\text { US \$ TO } \\
\text { CHINESE YUAN } \\
\text { EXCHANGE RATE }\end{array}$ & US 1 year T-BILL \\
\hline Mean & $0,06 \%$ & $0,04 \%$ & $0,02 \%$ & $0,00 \%$ & $0,01 \%$ & $-0,08 \%$ \\
\hline STD DEV & $1,27 \%$ & $1,60 \%$ & $1,63 \%$ & $1,21 \%$ & $0,11 \%$ & $4,47 \%$ \\
\hline Data Code & JSEOVER & CGSYSPT & CHSCOMP & SARCMUS & CHINYUS & H15/H15/ \\
\hline R & 2609 & 2609 & 2609 & 2609 & 2609 & 2609 \\
\hline
\end{tabular}

Source: DataStream, US Treasury

Figure 1: Risk factor changes of Portfolio Returns

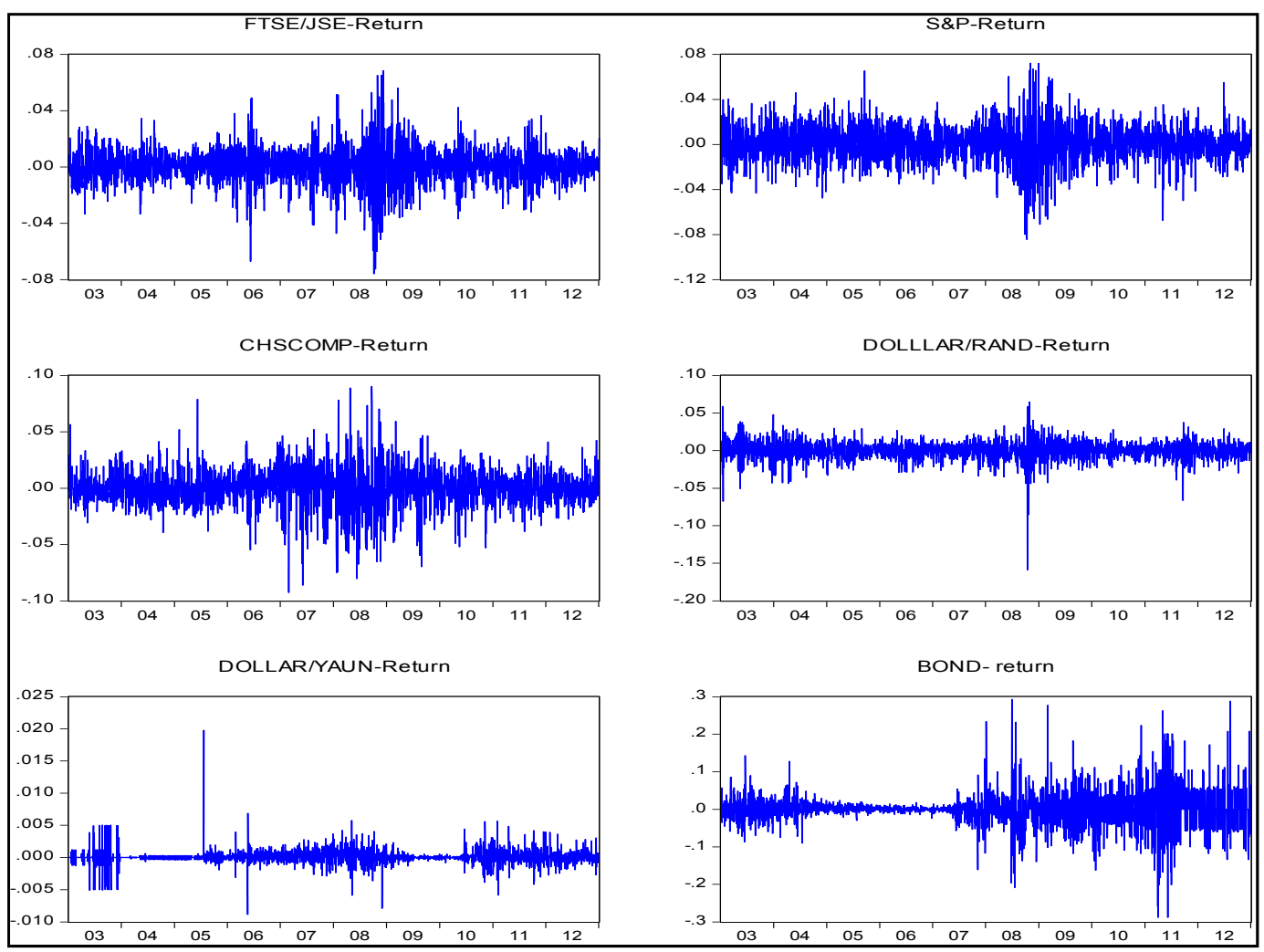


exposure on Dollar/Rand, and Dollar/Yaun exchanges along with the 90-day T- Bill return for the period 2003-2013. Figure 1 shows that the period between 2007 and 2009 was extreme and shows large negative returns. The dates are from the period of the subprime mortgage crisis and clearly the markets showed correlations with periods of market stress. The standardised total portfolio value and the portfolio weight are given as:

Linearised loss function is the first order Taylor approximation of the loss function and is equal to: 1

$L_{t+1}^{\Delta}=-\left[\frac{\partial V(t)}{\partial t} * \Delta+\frac{\partial V(t)}{\partial Z_{1}} * X_{1}(t+1)+\frac{\partial V(t)}{\partial Z_{4}} * X_{4}(t+1)+\frac{\partial V(t)}{\partial Z_{2}} * X_{2}(t+1)\right.$

$\left.+\frac{\partial V(t)}{\partial Z_{3}} * X_{3}(t+1)+\frac{\partial V(t)}{\partial Z_{5}} * X_{5}(t+1)+\frac{\partial V(t)}{\partial Z_{6}} * X_{6}(t+1)\right]$
Figure 2 shows the distribution of the portfolio losses during the period. The graph shows that there was high volatility during the subprime crisis and high portfolio losses. However, the FSTE/JSE market and the Rand-Dollar exchange seem less volatile as compared to the SSE Composite Index returns. The overall portfolio shows that the portfolio losses are likely to be during periods of high financial turmoil regardless of the portfolio positions. The greatest losses occurred during the financial crisis. Although the mean is -13123.60 , is it not significantly different from zero at the $5 \%$ significance level.

Figure 2: Distribution of Portfolio Losses

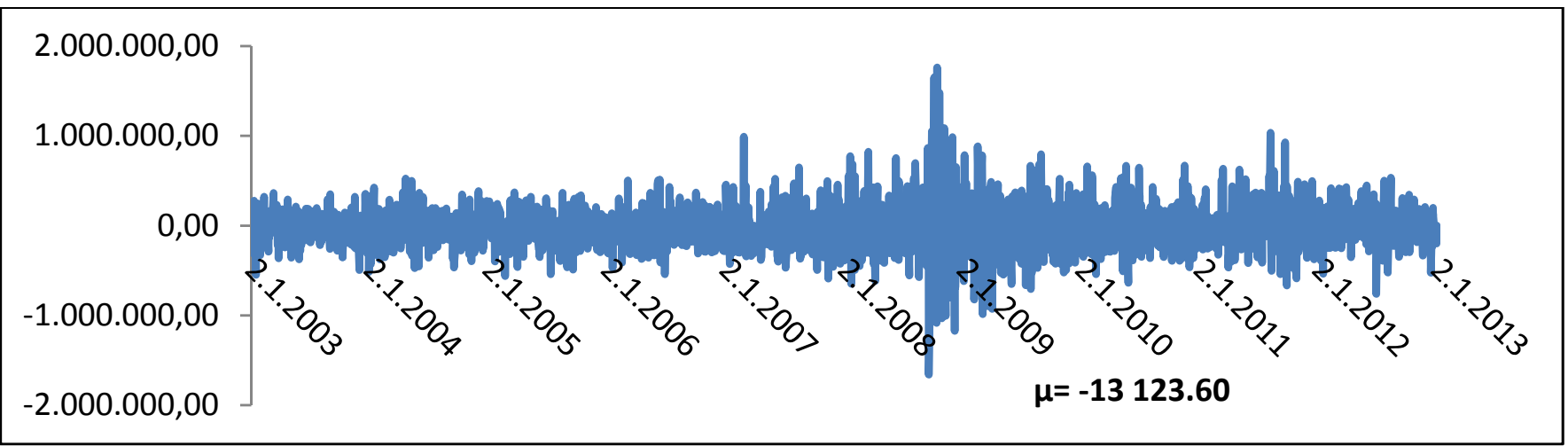

Table 2: Historical Simulation Method (1 Day Horizon)

\begin{tabular}{|l|c|c|c|}
\hline$A$ & 0.95 & 0.975 & 0.99 \\
\hline$V A R$ & $-395,229.97$ & $-601,150.65$ & $-748,623.47$ \\
\hline$E S$ & $-643,471.26$ & $-838,290.50$ & $-1,069,442.71$ \\
\hline
\end{tabular}

Variance Covariance Method (1 Day Horizon)

Table 3: Multivariate Normal

\begin{tabular}{|l|c|c|c|}
\hline$A$ & $95 \%$ & $97,5 \%$ & $99 \%$ \\
\hline VaR & $\$(335.236,53)$ & $\$(399.552,01)$ & $\$(474.332,65)$ \\
\hline$E S$ & $\$(420.523,51)$ & $\$(476.670,64)$ & $\$(543.496,83)$ \\
\hline
\end{tabular}

\footnotetext{
1 An interested reader may refer to the appendix for the portfolio
} mapping and risk factor changes. 


\section{Value-at-Risk and Expected Shortfall risk estimation models}

Both the HS and the variance covariance methods have shown that the ES method has more losses than the Value-at-Risk (VaR) method. However, the multivariate normal variance covariance method has few number losses compared to the HS method. For investors with less risk tolerance, it would be more advisable to adopt the HS model than the covariance technique.

The covariance matrix shows that there is a low correlation between the FTSE/JSE index and the two more developed market indices, the S\&P GSCl and $\mathrm{SCl}$. However, the FSTE/JSE is less volatile than the S\&P $\mathrm{GSCl}$ and $\mathrm{SCl}$ indices, as shown in Figure 1.

\section{Validity of Normality Assumption}

We applied the normality tests of the arbitrary group of indices and the exchange rate exposures. For each variable, the authors calculated sample skewness and kurtosis and applied the Jarque-Bera test to the multivariate time series. The null hypothesis of normality is not rejected at a p-value greater than 0.05 . We applied Mardia's test to the multivariate data for all of the log daily returns. The results are shown in the distribution graphs and the $\mathrm{QQ}$ plots and distribution graphs below.

Figures 3 and 4 show the daily log returns data on the normality assumption. The figures show that the daily log returns data fail to reject the multivariate test of normality. The QQ plots look slightly linear, thus showing some evidence that the returns are close to being normally distributed. This shows that there is a need for both the standard normal and student $t$ distribution. This might indicate the central limit theorem taking effect (Mc Neilet al., 2005). As expected, Figure 2 indicates that the currencies are the least volatile risk exposures in our log returns data, with the Yuan being the least volatile factor in our data. Figure 3 indicates that the returns show fatter tails than the normal distribution. However, as is the convention the authors will proceed under the assumption of univariate normality and therefore multivariate normality. In some cases the authors assume that the underlying

Table 4: Variance Covariance Matrix

\begin{tabular}{|l|c|c|c|}
\hline & FTSE/JSE & S\&P GSCI & $\begin{array}{c}\text { SHANGHAI SE COMPOSITE - } \\
\text { PRICE INDEX }\end{array}$ \\
\hline FTSE/JSE & $0,016 \%$ & $0,007 \%$ & $0,003 \%$ \\
\hline S\&P GSCI & $0,007 \%$ & $0,026 \%$ & $0,003 \%$ \\
\hline $\begin{array}{l}\text { SHANGHAI SE COMPOSITE - } \\
\text { PRICE INDEX }\end{array}$ & $0,003 \%$ & $0,003 \%$ & $0,026 \%$ \\
\hline
\end{tabular}

Table 5: Student-t

\begin{tabular}{|c|c|c|c|}
\hline \multicolumn{4}{|l|}{ VaR } \\
\hline & $95 \%$ & $97,5 \%$ & $99 \%$ \\
\hline$v=3$ & $\$(831.474,32)$ & $\$(1.124 .571,33)$ & $\$(1.604 .741,59)$ \\
\hline$v=4$ & $\$(614.866,58)$ & $\$(800.928,29)$ & $\$(1.081 .061,36)$ \\
\hline$v=5$ & $\$(530.475,37)$ & $\$(676.857,29)$ & $\$(886.166,38)$ \\
\hline$v=6$ & $\$(485.262,90)$ & $\$(611.183,74)$ & $\$(785.106,24)$ \\
\hline \multicolumn{4}{|l|}{ ES } \\
\hline$V=3$ & $\$(790.300,23)$ & $\$(1.028 .100,14)$ & $\$(1.428 .900,08)$ \\
\hline$v=4$ & $\$(653.200,14)$ & $\$(814.600,48)$ & $\$(1.065 .100,98)$ \\
\hline$v=5$ & $\$(589.400,55)$ & $\$(718.280,69)$ & $\$(908.280,13)$ \\
\hline$v=6$ & $\$(552.790,88)$ & $\$(664.110,73)$ & $\$(822.570,45)$ \\
\hline
\end{tabular}


Figure 3: Distribution of Returns

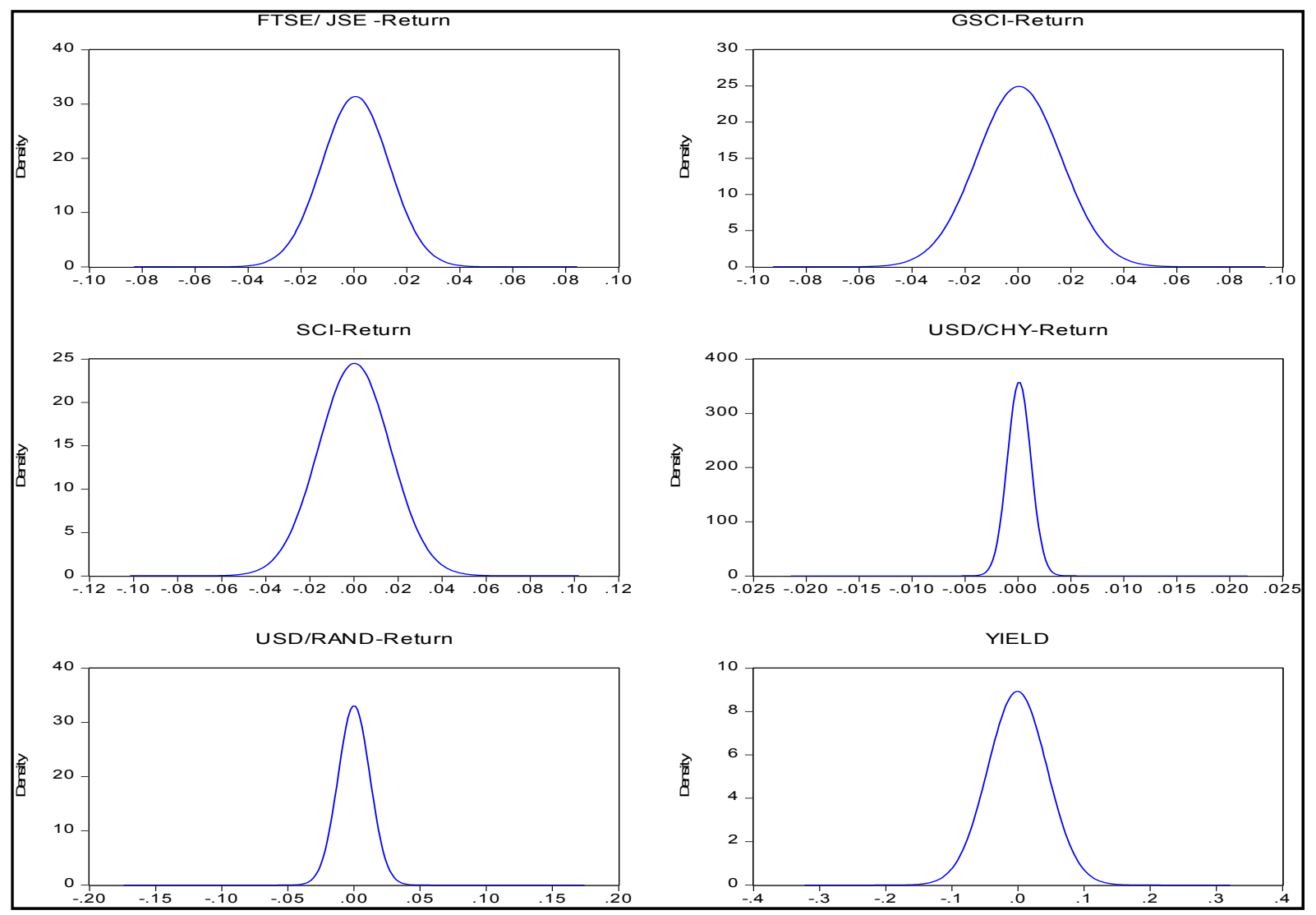

Figure 4: $Q Q$ Plot of daily log-returns

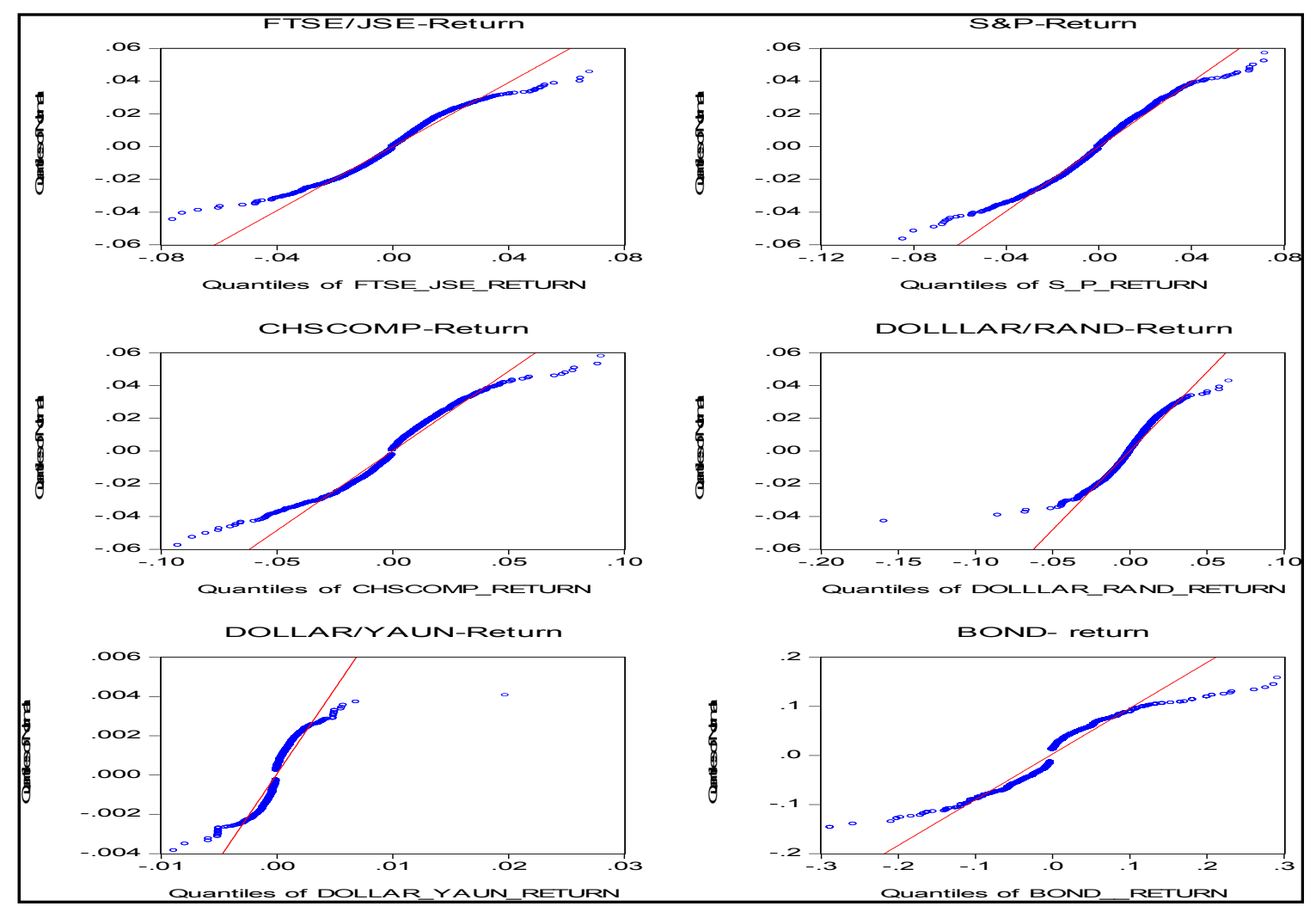


distributions follow a student-t distribution so that we are better able to capture the fat tails observed in the data.

Table 6 shows an analysis of daily log- returns data for the period 2003-2013, and ML estimates of parameters and standard errors for a GARCH $(1,1)$ model with a leverage term under the $t$ innovation assumption. The GARCH $(1,1)$ process with Gaussian innovations and parameters are given above for both standard normal and the student $t$ distributions.

The back testing results shown in Table 7 suggest that the number of violations for all models (excluding the Variance Covariance method: Student-t v=3) far exceeded the expected number of violations in the global financial crisis $(2008,2009)$. Furthermore, all models that assumed multivariate normality for the underlying risk factors had on average a higher number of violations than the student-t. This is because the student-t, with its heavier tails, is far more able to capture the observed nature of financial losses than the normal distribution. Thus, the lower the number of degrees of freedom, the lower the number of expected violations.

Table 6: $\operatorname{GARCH}(1,1)$ results

\begin{tabular}{|c|c|c|}
\hline Parameter & Normal & Student-t \\
\hline$\mu$ & $-17022,76$ & $-19241,84$ \\
\hline$\alpha 0$ & $581.452 .475,81$ & $508.053 .397,86$ \\
\hline$\alpha 1$ & 0,05 & 0,05 \\
\hline$\beta 1$ & 0,94 & 0,94 \\
\hline$N$ & & 10,19 \\
\hline
\end{tabular}

\begin{tabular}{|l|c|c|c|}
\hline Critical Values & 0,95 & 0,975 & 0,99 \\
\hline normal & 1,644853627 & 1,95996398 & 2,32634787 \\
\hline student-t & 1,812461123 & 2,22813885 & 2,76376946 \\
\hline VAR & 0,95 & 0,975 & 0,99 \\
\hline normal & $355.462,15$ & $426.820,38$ & $509.789,75$ \\
\hline student-t & $391.069,82$ & $485.172,48$ & $606.430,52$ \\
\hline
\end{tabular}

Table 7: Back Testing GARCH

\begin{tabular}{|c|c|c|c|c|c|c|c|c|c|c|c|}
\hline & 2003 & 2004 & 2005 & 2006 & 2007 & 2008 & 2009 & 2010 & 2011 & 2012 & 2013 \\
\hline Trading Days & 260 & 262 & 260 & 260 & 261 & 262 & 261 & 261 & 260 & 261 & 1 \\
\hline \multicolumn{12}{|c|}{ Expected Number of Violations } \\
\hline (95\% VaR) & 13 & 13 & 13 & 13 & 13 & 13 & 13 & 13 & 13 & 13 & 0 \\
\hline (97.5\% VaR) & 7 & 7 & 7 & 7 & 7 & 7 & 7 & 7 & 7 & 7 & 0 \\
\hline (99\% VaR) & 3 & 3 & 3 & 3 & 3 & 3 & 3 & 3 & 3 & 3 & 0 \\
\hline \multicolumn{12}{|c|}{ Number of Violations } \\
\hline \multicolumn{12}{|l|}{ Normal } \\
\hline 0.95 & 6 & 8 & 7 & 7 & 10 & 34 & 37 & 14 & 17 & 6 & 0 \\
\hline 0.975 & 3 & 4 & 5 & 2 & 5 & 23 & 25 & 6 & 7 & 4 & 0 \\
\hline 0.99 & 3 & 4 & 5 & 2 & 5 & 23 & 25 & 6 & 7 & 4 & 0 \\
\hline \multicolumn{12}{|l|}{ Student-t } \\
\hline 0.95 & 3 & 5 & 7 & 4 & 7 & 27 & 34 & 8 & 10 & 5 & 0 \\
\hline 0.975 & 3 & 0 & 3 & 1 & 2 & 17 & 19 & 4 & 5 & 4 & 0 \\
\hline 0.99 & 0 & 0 & 0 & 0 & 0 & 12 & 9 & 1 & 1 & 1 & 0 \\
\hline
\end{tabular}




\section{CONCLUSION AND RECOMMENDATIONS}

The most appropriate VAR modeling approach is one that adopts a heavy tailed multivariate distribution (in this case the $t$-distribution) of the essential risk factors. The models in our portfolio that made use of the t-distribution performed relatively better in back testing, implying that they were better able to estimate the VAR and ES. This is because, in line with the stylised facts of the empirical findings, our results did indeed suggest that the distributions of the financial risk factors of our portfolio returns are heavier tailed than the normal distribution, thus prompting the use of a heavy tailed distribution like the student $t$. As a result of this, the authors saw that the assumption of Gaussian risk factors tended to underestimate the tail of the loss distribution. They experienced the highest number of violations, especially during the period of the global financial crisis.

The authors further recommend the use of both the conditional and unconditional Variance Covariance method. This is because this method is relatively easy to implement and provides fairly accurate estimates. One drawback of this method, however, is that it makes use of linearisation to approximate losses and this may not always offer a good approximation of the relationship between true loss distribution and the risk factor changes. In addition, the authors recommend the use of a GARCH structure with a heavy tailed multivariate distribution such as the t-distribution.

\section{REFERENCES}

Barry, C. B., \& Rodriguez, M. 2004. Risk and return characteristics of property indices in emerging markets. Emerging Markets Review 5: 131-159.

Berger, T. 2013. Forecasting value-at-risk using time varying copulas and EVT return distributions. Journal of International Economics 133: 93-106.

Chen, Q., \& Chen R. 2013. Method of Value-at-Risk and empirical research for Shanghai stock market. Procedia Computer Science 17: 671-677.
Cheng, G., Li P., \& Shi, P. 2007. A new algorithm based on copulas for $V a R$ valuation with empirical calculations. Journal of Theoretical Computer Science 378: 190-197.

Fan, Y., Wei, Y., \& Xu, W. 2004. Application of VaR methodology to risk management in the stock market in China. Journal of Computers \& Industrial Engineering 46: 383-388.

Girard, E., Rahman H., \& Zaher, T. 2003. On market price of risk in Asian capital markets around Asian Flu. International Review of Financial Analysis 12: 241-265.

Gourieroux, C., Laurent, J. P., \& Scaillet, O. 2000. Sensitivity analysis of Value at Risk.Journal of Empirical Finance 7: 225-245.

Haas M. 2009. Value- at- Risk via mixture distributions reconsidered. Journal of applied mathematics and Computation 215: 2103-2119.

Lee, C., Shie, F. S., \& Chang, Y. C. 2012. How Close a relationship does a capital market have with another such market? The case of Taiwan from the Asian Financial crisis. Pacific- Basin Finance Journal 20: 349-362.

Longin, F. M. 2000. From value at risk to stress testing: The extreme value approach. Journal of Banking \& Finance 24: 1097-1130.

McNeil, A. J., Frey, R., \& Embrechts, P. 2005. Quantitative Risk Management: Concepts, Techniques and Tools. Oxfordshire, Princeton University Press.

McNeil, A.J., Frey, R., and Embrechts, P. 2006. Quantitative Risk Management: Concepts, Techniques, and Tools. Oxfordshire, Princeton University Press.

Prem, K. P., Ng, D., Pasman, H. J., Sawyer, M., Guo Y., \&Mannan, M. S. 2010. Risk measures constituting a risk metrics which improved decision making: Value- at- Risk. Journal of Loss Prevention in the Process Industries 23: 211-219.

Rockafellar T. R.,\& Uryasev S. 2002. Conditional Value-atrisk for general loss distributions. Journal of Banking \& Finance 26: 1443-1471.

Rossignolo A. F., Fethi M. D., \& Shaban M. 2012. Value- atRisk models and Basel capital charges Evidence from Emerging and Frontier stock markets. Journal of Financial Stability 8: 303-319.

Yamai Y. and Yoshiba T. 2005. Value- at- risk versus expected shortfall: A practical perspective. Journal of Banking \& Finance 29: 997-1015. 


\section{Portfolio Mapping 6}

\section{Risk Factors}

1. FTSE JSE index (measured in log(index value))

2. Goldman Sachs Commodity Index (measured in log(index value))

3. Shanghai composite index (measured in log(index value))

4. USD/CNY exchange rate (the number of USD per CNY, measured in log(exchange rate))

5. USD/ZAR exchange rate (the number of USD per ZAR, measured in log(exchange rate))

6. 1-year UST interest rate

\section{Logarithmic Prices}

$Z_{1}(t)=\ln \left(S_{1}(t)\right)$, "the log value of the FTSE/JSE index"

$Z_{2}(t)=\ln \left(S_{2}(t)\right)$, "the log value of the GSCl commodity index"

$Z_{3}(t)=\ln \left(S_{3}(t)\right)$, "the log value of the Shanghai composite index"

$Z_{4}(t)=\ln \left(S_{4}(t)\right)$, "the log value of the USD/ZAR exchange rate, the number of USD per 1 ZAR"

$Z_{5}(t)=\ln \left(S_{5}(t)\right)$, "the log value of the USD/CNY exchange rate, the number of USD per 1 CNY"

$Z_{6}(t)=y(t, T)$, "the 1-year UST interest rate"

$Z(t)=\left(Z_{1}(t), Z_{2}(t), Z_{3}(t), Z_{4}(t), Z_{5}(t), Z_{6}(t)\right)$

\section{Risk Factor Changes}

$$
X(t+1)=\left(X_{1}(t+1), X_{2}(t+1), X_{3}(t+1), X_{4}(t+1), X_{5}(t+1), X_{6}(t+1)\right):=Z(t+1)-Z(t)
$$

\section{Loss Operator}

$$
L(t+1)=-(f(t+1, Z(t+1))-f(t, Z(t)))
$$

\section{Exposures}

$w_{1}=\frac{2 V^{*}(1 / 3) \lambda}{\exp \left(Z_{1}(0)+Z_{4}(0)\right)}$, the position in the FTSE/JSE index

\footnotetext{
${ }^{6}$ For this estimation I am grateful to a reference for checking the accuracy
} 
$w_{2}=\frac{2 V^{*}(1 / 3) \lambda}{\exp \left(Z_{2}(0)\right)}$, the position in the GSCl commodity index

$w_{3}=\frac{2 V^{*}(1 / 3) \lambda}{\exp \left(Z_{3}(0)+Z_{5}(0)\right)}$, position in the Shanghai composite index

$w_{4}=\frac{V}{\exp \left(-(T-t) * Z_{6}(0)\right)}=\frac{V}{\exp \left(-Z_{6}(0)\right)}$ the number of UST bills shorted

\section{Portfolio Value}

$V(t)=f(t, Z(t))$

$V(t)=w_{1} * \exp \left(Z_{1}(t)+Z_{4}(t)\right)+w_{2} * \exp \left(Z_{2}(t)\right)+w_{3} * \exp \left(Z_{3}(t)+Z_{5}(t)\right)-w_{4} * \exp \left(-(T-t) * Z_{6}(t)\right)$

\section{Portfolio Loss}

$L(t+1)=-(V(t+1)-V(t))=$

$\left.=w_{1}^{*} * \exp \left(Z_{1}(t)+Z_{4}(t)\right)+w_{2}^{*} \exp \left(Z_{2}(t)\right)+w_{3} * \exp \left(Z_{3}(t)+Z_{5}(t)\right)-w_{4} * \exp \left(-(T-t) * Z_{6}(t)\right)\right)$

$-\left[w_{1}^{*} \exp \left(Z_{1}(t+1)+Z_{4}(t+1)\right)+w_{2} * \exp \left(Z_{2}(t+1)\right)+w_{3} * \exp \left(Z_{3}(t+1)+Z_{5}(t+1)\right)-w_{4} * \exp \left(-(T-t-1) * Z_{6}(t+1)\right)\right]=$

$=w_{1}^{*} \exp \left(Z_{1}(t)+Z_{4}(t)\right) *\left(1-\exp \left(X_{1}(t+1)+X_{4}(t+1)\right)\right)+w_{2}^{*} \exp \left(Z_{2}(t)\right) *\left(1-\exp \left(X_{2}(t+1)\right)\right)+w_{3} * \exp \left(Z_{3}(t)+Z_{5}(t)\right) *\left(1-\exp \left(X_{3}(t+1)+X_{5}(t+1)\right)\right)$

$-w_{4}^{*} *\left[\exp \left(-(T-t) * Z_{6}(t)\right)-\exp \left(-(T-t-1) * Z_{6}(t+1)\right)\right]$

$\approx w_{1}^{*} \exp \left(Z_{1}(t)+Z_{4}(t)\right) *\left(1-\exp \left(X_{1}(t+1)+X_{4}(t+1)\right)\right)+w_{2} * \exp \left(Z_{2}(t)\right) *\left(1-\exp \left(X_{2}(t+1)\right)\right)+w_{3} * \exp \left(Z_{3}(t)+Z_{5}(t)\right) *\left(1-\exp \left(X_{3}(t+1)+X_{5}(t+1)\right)\right)$

$-w_{4} *\left[\exp \left(-(T-t) Z_{6}(t)\right)\right]\left[1-\exp \left(-X_{6}(t+1)\right)\right]$

$\left.=a^{*}\left(1-\exp \left(X_{1}(t+1)+X_{4}(t+1)\right)\right)+b^{*}\left(1-\exp \left(X_{2}(t+1)\right)\right)+c^{*}\left[1-\exp \left(X_{3}(t+1)+X_{5}(t+1)\right)\right)\right]-d^{*}\left[1-\exp \left(X_{6}(t+1)\right)\right]$

where

$a=w_{1}^{*} \exp \left(Z_{1}(t)+Z_{4}(t)\right)$

$b=w_{2} * \exp \left(Z_{2}(t)\right)$

$c=w_{3}^{*} \exp \left(Z_{3}(t)+Z_{5}(t)\right)$

$d=w_{4} * \exp \left(-(T-t) Z_{6}(t)\right)$. 
Taking the derivatives of the value of the portfolio with respect to time and the risk factors:

$$
\begin{aligned}
& \frac{\partial V(t)}{\partial t}=-w_{4} * \exp \left(-(T-t) * Z_{6}(t)\right) * Z_{6}(t) \\
& \frac{\partial V(t)}{\partial Z_{1}}=\frac{\partial V(t)}{\partial Z_{4}}=w_{1} * \exp \left(Z_{1}(t)+Z_{4}(t)\right) \\
& \frac{\partial V(t)}{\partial Z_{2}}=w_{2} * \exp \left(Z_{2}(t)\right) \\
& \frac{\partial V(t)}{\partial Z_{3}}=\frac{\partial V(t)}{\partial Z_{5}}=w_{3}^{*} \exp \left(Z_{3}(t)+Z_{5}(t)\right) \\
& \frac{\partial V(t)}{\partial Z_{4}}=-w_{4} * \exp \left(-(T-t) * Z_{6}(t)\right) *-(T-t)=w_{4} * \exp \left(-(T-t)^{*} Z_{6}(t)\right) *(T-t)
\end{aligned}
$$

